\title{
The impact of childhood mortality on fertility in six rural thanas of Bangladesh
}

Mian Bazle Hossain

James F. Phillips

Population Council

Thomas K. LeGrand

Follow this and additional works at: https://knowledgecommons.popcouncil.org/departments_sbsr-pgy

Part of the Demography, Population, and Ecology Commons, Family, Life Course, and Society Commons, International Public Health Commons, and the Maternal and Child Health Commons How does access to this work benefit you? Let us know!

\section{Recommended Citation}

Hossain, Mian Bazle, James F. Phillips, and Thomas K. LeGrand. 2005. "The impact of childhood mortality on fertility in six rural thanas of Bangladesh," Policy Research Division Working Paper no. 198. New York: Population Council. Version of record: https://doi.org/10.1353/dem.2007.0047 


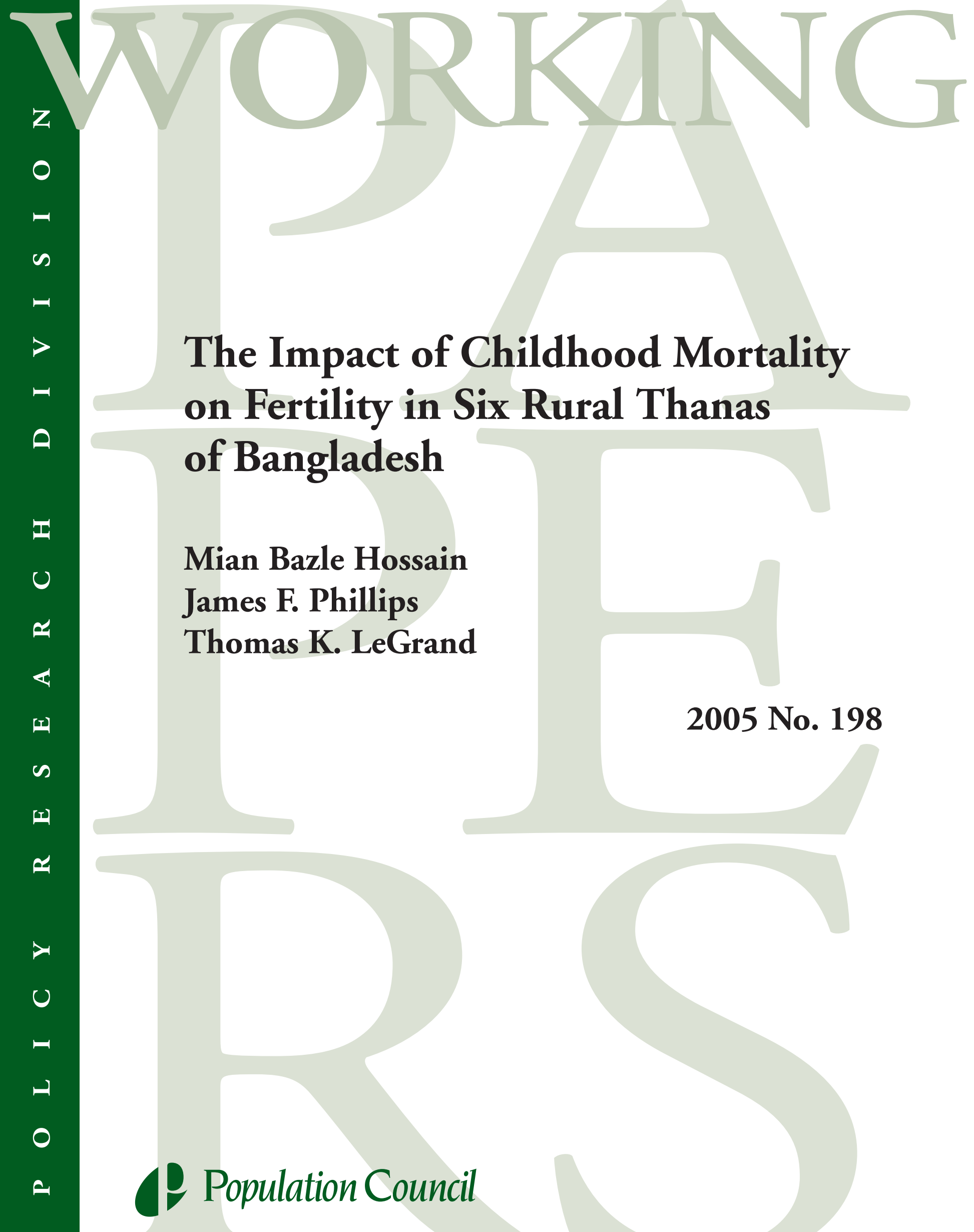




\section{(P) Population Council}

One Dag Hammarskjold Plaza

New York, New York 10017 USA

www.popcouncil.org

pubinfo@popcouncil.org

This material may not be reproduced without written permission from the authors. For a list of Policy Research Division Working Papers, including those that are currently available for downloading in PDF format, see www.popcouncil.org/publications/wp/prd/rdwplist.html.

ISSN: $1554-8538$

(C) 2005 The Population Council, Inc. 


\title{
The Impact of Childhood Mortality on Fertility in Six Rural Thanas of Bangladesh
}

\author{
Mian Bazle Hossain \\ James F. Phillips \\ Thomas K. LeGrand
}

Mian Bazle Hossain is Assistant Professor, Public Health Program, Morgan State University, Baltimore, MD (mbhossain@moac.morgan.edu). James F. Phillips is Senior Associate, Policy Research Division, Population Council (jphillips@popcouncil.org). Thomas K. LeGrand is Professor, Département de démographie, University of Montréal, CIED. (tk.legrand@umontreal.ca). This paper builds upon models proposed by Kenneth Hill and his colleagues at a Rockefeller Foundation-funded seminar on childhood replacement in Africa. Analysis is based on data collected by the Maternal and Child Health and Family Planning Extension Project of the International Centre for Diarrhoeal Disease Research, Bangladesh (ICDDR,B). The Extension Project was funded by grants to the ICDDR,B and to the Population Council by the United States Agency for International Development.

This material may not be reproduced without written permission from the authors. For a list of Policy Research Division Working Papers, including those available for downloading in PDF format, see www.popcouncil.org/publications/wp/prd/rdwplist.html.

(C) 2005 The Population Council, Inc. 


\begin{abstract}
This paper examines the causal structure of the relationship between child mortality events and subsequent fertility with an analysis of prospective longitudinal data on births and childhood deaths occurring to nearly 8,000 mothers observed in Bangladesh over the 1982-93 period, a time of rapid decline in fertility. Generalized hazard-regression analyses are employed to assess the effect of infant and child mortality on the hazard of conception, controlling for birth order and maternal age and educational attainment. Results show that childhood mortality increases the hazard of birth-interval closure if the death occurs in the index interval, representing the combined effect of biological and volitional replacement. Substantial birthinterval effects are also evident if the death occurs during a prior birth interval, signifying a volitional replacement effect alone. Moreover, mortality effects in prior birth intervals are consistent with the hypothesis of insurance effects. Interaction of replacement with elapsed time suggests that the volitional impact of child mortality increases as the demographic transition progresses. This volitional effect interacts with sex of the index child. Investigation of higherorder interactions suggests that this gender-replacement effect has not changed with time.
\end{abstract}


A widely accepted hypothesis holds that high childhood mortality contributes to parental desires to have many children. Conversely, declining childhood mortality increases the number of surviving children, leading couples to compensate with fertility control. Empirical investigation of the interrelationship of reproductive behavior and childhood mortality has focused on two specific domains of fertility responses to childhood mortality: an insurance effect that arises from the tendency of couples in high-mortality settings to anticipate mortality risks and a replacement effect in which parents experiencing the death of a child adjust their subsequent reproductive preferences and behavior. Replacement, in turn, has two components: a biological component associated with the death of breastfeeding infants that arises from the truncation of lactational amenorrhea and a volitional component that arises from parental decisions to try to have an additional child to replace the lost child. Testing the insurance and replacement hypotheses involves clarifying the relationship between the death of a child and the mechanisms of fertility decisionmaking. Both quantitative survey-data analyses and qualitative social research suggest that child replacement is more pronounced in settings where fertility regulation is widespread than in settings where prevalence of contraceptive use is relatively low (Mensch 1985; Rahman et al. 1992; Hill et al. 2001; LeGrand et al. 2003; LeGrand and Sandberg 2005).

Research has determined that the death of a child reduces the probability that parents will subsequently adopt a contraceptive method, thereby increasing the likelihood of additional pregnancies. Qualitative research conducted in Bangladesh and India by Amin and Basu (2004) suggests that if more children are expected to survive to maturity, parents can afford to have fewer children. Whether Bangladeshi parents adjust fertility in response to mortality events has yet to be investigated, however. Bangladesh, like nearly all other developing countries, has been experiencing mortality and fertility reductions that are shaped by programs and policies (Montgomery and Cohen 1998; Wolpin 1998).

Bangladesh witnessed a rapid fertility transition during the 1980s and 1990s. Studies conducted in Bangladesh have consistently shown that dramatic and sustained increases in contraceptive use explain this transition. ${ }^{1}$ The total fertility rate declined from 6.5 to 3.5 during the 1980-95 period. Other research has consistently demonstrated the behavioral determinants and child survival consequences of gender bias. Girls experience excess mortality risks as children (D'Souza and Chen 1980). Although this effect is not prominent among breastfeeding children, excess mortality in the postweaning period arises from the selective neglect of girls in the allocation of household resources (Chen et al. 1981). ${ }^{2}$ Childhood mortality rates are particularly high for girls in the postweaning ages as a result of selective deprivation of health care and other familial resources. Gender bias is also reflected in reproductive behavior. For example, contraceptive adoption and continuation rates are higher if the last-born child is male than if it is female (Clark 1996; Rahman 1998). Moreover, survey research indicates that the preference for sons has remained resilient in Bangladesh. Average desired total fertility remains at three children; couples typically want to have two sons and a daughter. This paper examines the proposition that gender bias interacts with insurance and replacement motives. If volitional replacement is evident in the context of Bangladesh, the death of a male child is likely to have a greater effect on subsequent fertility than the death of a female child. 
Our analysis is derived from the longitudinal observation of nearly 8,000 married women of reproductive age in six rural districts of Bangladesh over a 12-year period starting in January of 1982 and extending to December of 1993. The pace of reproductive change in this period ranks among the most rapid ever recorded. However, despite a substantial decline in child mortality during this period, infant mortality remained high by global standards and largely unchanged. We investigate the volitional context of the impact of childhood mortality on fertility during this period of rapid reproductive change, first by testing the hypothesis of the volitional response to child replacement and then by estimating the conditionality of replacement and insurance with stage of transition. If child-replacement motives exist, decisions should be reflected by the interaction of replacement behavior with son preference and increasing fertility control. Insurance effects are linked less to prevailing fertility circumstances than to perceptions of child mortality risks, however. Thus, insurance behavior is expected either to be constant as fertility change progresses or to be concentrated in the early stage of transitions when mortality risks are perceived to be high.

\section{The Statistical Model}

The analysis presented here is based on the interval between a given birth (the "index birth") and the next conception, employing the strategy proposed by Hill et al. (2001) in a paper on child insurance and replacement effects in Zimbabwe and Senegal. ${ }^{3}$ In keeping with this model, we have defined four mortality variables for each child with respect to a given mother: the death of a child prior to the birth of the index child ( mort $\left._{1}\right)$; the death of a child born during the interval before the conception of the index child $\left(\mathrm{mort}_{2}\right)$; the death of the index child during the specified interval (mort 3 ); and the death of a child in the 12 months following the end of the interval $\left(\mathrm{mort}_{4}\right)$ defining parameters of the hazard model:

$$
\ln h(t / x, z)=p\left(t^{p-1}\right)+\sum_{j=1}^{J} \beta_{j} X_{i j}+\sum_{k=1}^{K} \gamma_{k} Z_{i k}+\sum_{\ell=1}^{4} \delta_{l} \cdot \text { mort }_{i \ell}+\sum_{k=1}^{K} \sum_{l=1}^{4} \eta_{i k l} Z_{i k} \cdot \text { mort }_{i l}+\varepsilon_{i j}+\varepsilon_{i},
$$

where $t$ is the number of months from the onset of the index-birth interval to the time of the conception that closes the interval, the time to the end of the study period, or the time to loss to follow-up; and $h(t / x, z)$ is the hazard function for conception at time $t$ conditional on the set of maternal characteristics $X$, and child characteristics $Z ; p$ is the shape parameter of the Weibull distribution to be estimated; $X_{i j}$ represents a vector of $J$ background characteristics of individual mother $i ; Z_{i j}$ is the birth order of the index child, sex of the index child, and year of the birth of the index child; mort $_{i \ell}$ represents the effect of the death of a child prior to the birth of the index child (mort 1 ), the death of a child born during the interval before the conception of the index child $\left(\mathrm{mort}_{2}\right)$, the death of the index child during the specified interval ( mort $\left._{3}\right)$, and the death of a child in the 12 months following the end of the interval $\left(\mathrm{mort}_{4}\right) ; \boldsymbol{\beta}, \boldsymbol{\gamma}, \delta, \eta$ are vectors of parameters to be estimated by the maximum likelihood; and $\varepsilon_{i j}$ and $\varepsilon_{i}$ are error terms for the within- and between-mother effects, respectively. 
A specification of (1) is employed that estimates $\eta$ for interactions between sex of child, year of birth, and mortality type and the reduced form with interactions omitted. Likelihood ratios for reduced-form specifications of (1) permit tests of the statistical significance of sets of interactions.

As Hill and his colleagues (2001) note, each mortality parameter in (1) has a corresponding hypothesis concerning its role in replacement-reproductive decisionmaking:

Mort $_{1}$ represents a mother's experience of a child's death prior to her conception of the index child. Mort 1 , therefore, is comprised of both insurance and replacement components, a characteristic of the behavioral response to mortality that Hill and his colleagues have labeled "hoarding." Mort 1 effects would arise if the closure of an index-birth interval is explained by mortality events in the past.

Mort $_{2}$ concerns the death of a child during the interval leading to the conception of the index child and, therefore, cannot possibly be related to biological replacement of the index child. Parameters associated with mort $_{2}$, therefore, directly test the hypothesis of child replacement.

Mort $_{3}$ controls for biological effects that arise from truncation of breastfeeding and lactational amenorrhea resulting from the death of an infant. Volitional response to the death of a child may also occur in the index interval, however, because mort 3 also captures the effect of reproductive decisions of parents that arise in response to the death of an infant. Mort ${ }_{3}$ is, therefore, comprised of both biological and volitional replacement components. Interaction of mortality events with sex of the index child, with time period of conception, and with birth order test hypotheses regarding the conditionality of biological and behavioral child mortality effects on conception. As a result of strong gender bias in this setting, we posit that the death of a male child will be associated with a stronger replacement effect than will the death of a female child.

Events following a birth interval, mort $_{4}$, cannot possibly explain child-replacement behavior during the interval. Therefore, they capture exogenous familial risks unrelated to insurance or replacement behavior, such as household conditions, maternal health, and other factors that are potentially confounding effects in the estimation of insurance and replacement effects. Mort 4 addresses the possibility that many factors that contribute to the survival of a child and the closing of birth intervals are complex and not unidirectional, such as the determinants of family-building strategies, differential access to health or family planning services, family resources for health and nutritional resources, maternal depletion associated with closely spaced births, and others.

\section{The SAMPle Registration System}

Data for the present analysis are derived from birth histories for the period prior to the onset of longitudinal surveillance operations in 1982 and from prospective birth and mortality data recorded by the Sample Registration System (SRS), a longitudinal cluster-sample demographic surveillance system that was established as the demographic evaluation mechanism for the Bangladesh Maternal and Child Health and Family Planning (MCH-FP) Extension Project. This initiative, subsequently renamed the Operations Research Project (ORP), is a 
collaborative field experiment of the International Centre for Diarrhoeal Disease Research, Bangladesh (ICDDR,B) and the Ministry of Health and Family Welfare of the Government of Bangladesh. As the research partner in this collaboration, the ORP conducts research designed to improve public-sector maternal and child health and family planning services. In its original design, the ORP was fielded to test strategies for replicating services of the Matlab Family Planning-Health Services Project.

The initial SRS sample was a randomized cluster sample of approximately 8,000 households dispersed in four rural thanas. ${ }^{4}$ Longitudinal monitoring extended over the 1982-93 period in four thanas, Sirajganj and Gopalpur in rural central Bangladesh on the west and east banks of the Jamuna river, respectively, and Abhoynagar and Fultala on the country's rural western border with West Bengal State in India. Study thanas for the present analysis are within Sirajganj, Gopalpur, Abhoynagar, and Fultala thanas. In 1986, random cluster samples for two additional rural districts, Bagerpara and Keshobpur in rural southeastern Bangladesh, near Chittagong, were added to the surveillance system. Although the duration of observation was shorter in the Bagerpara and Keshobpur thanas, data from this area are left-censored and included in the analysis. Longitudinal data collection in Gopalpur and Fultala was terminated at the end of 1989 because of funding constraints. Data from these thanas are right-censored at this termination date. Longitudinal data for the entire study period are available for Sirajganj and Abhoynagar. The baseline fertility-history data for all women of reproductive age in the six study thanas were compiled and used in this research for defining mortality events prior to the baseline.

Although all study areas of the SRS are rural, the Abhoynagar and Fultala populations are connected by a highway that joins the port city of Khulna and the regional headquarters in the city of Jessore. A small but economically significant commercial sector in the towns along this road makes the western sample areas somewhat more developed than the SRS sample areas in central Bangladesh, which remain isolated, impoverished, and remote.

At the launching of surveillance, a detailed baseline fertility history was conducted for all ever-married women in study. After the baseline, a team of professional ICDDR,B interviewers visited sample households once every three months to collect data concerning demographic events-births, deaths, changes in marital status, migration into and out of households, changes in household relationships, and household splits and mergers. ${ }^{5}$ In each round, interviewers also asked women of reproductive age questions about the possible onset of pregnancy by seeking information about the date of their last menstrual period (LMP). When this date has not changed from that recorded at the previous round, the probable reason is sought and recorded. This information is used to alert interviewers to possible conceptions and pregnancy losses. Although early pregnancy losses may not be completely reported in the process, the SRS prospective interviewing procedure is likely to provide an unusually complete registration of conception rates and an accurate detection of late-term pregnancy and perinatal events. ${ }^{6}$

Although the SRS resembles the relational design of the Matlab Demographic Surveillance System in certain respects, it was designed to be a statistically efficient longitudinal study of a baseline population of more than two million residents dispersed within four rural 
districts. Stages of the sample design were intended to fulfill research goals of the MCH-FP Extension Project. Clusters were larger than health-worker assignment areas, so that service work routines could not be readily concentrated in sample areas. As a consequence, clustering has introduced an element of statistical inefficiency in the design. Nonetheless, the sample avoids the pitfall of concentrating research in a single surveillance zone, improving prospects that research will be representative of a larger study population.

Sample extended households comprise the unit of observation, and procedures for monitoring in- and out-migration from extended households, as well as household splitting and merging, renew the longitudinal cohort over time. Thus, the SRS is a longitudinal open cohort of extended family households.

The incidence of biological replacement caused by the truncation of lactation and postpartum amenorrhea following the death of a child has been established in Bangladesh (Chen et al. 1974) and elsewhere (Montgomery and Cohen 1998). Because breastfeeding data were not recorded by the Extension Project, however, decomposing mort $_{3}$ effects into behavioral and biological components is not possible in this analysis.

\section{BACKGROUND}

The study period for the present analysis corresponds to a period of unprecedented demographic change in Bangladesh. In Bangladesh as a whole, fertility declined by more than 50 percent in the 1980s and 1990s. As Table 1 shows, the total fertility rate (TFR) declined from 4.4 children per woman of reproductive age to 2.9 children during the 1983-93 period in the study population. Childhood mortality also declined. In the study period, the child mortality rate declined by more than 50 percent as a consequence of the successful expansion of immunization coverage and other childhood health interventions. The infant mortality rate in study areas remained above 100 during the research period, demonstrating that preventive health programs were more effective in preventing late-childhood mortality than infant mortality.

Social characteristics of the study population have shown that the areas selected for this research remain isolated, traditional, and similar in most respects to characteristics of the rural hinterland of Bangladesh. Although the proportion of women who had ever attended school remained low in the study period, improvements in educational attainment among young women increased the mean years of schooling by 0.3 years during the study period. The percentage of intervals associated with mort $_{1}$, mort $_{2}$, mort $_{3}$, and mort $_{4}$ are 9.33, 1.17, 3.71, and 0.20, respectively. 
Table 1 Descriptive statistics for the study population of six rural SRS thanas of Bangladesh, 1983 and 1993

\begin{tabular}{lrrr}
\hline Statistic & $\mathbf{1 9 8 3}$ & $\mathbf{1 9 9 3}$ & \\
\hline & & & \\
Infant mortality rate (per 1,000 live births) & 119 & 106 & \\
Child mortality rate (1-4 years) (per 1,000 live births) & 11 & 5 & \\
Total fertility rate (per woman of reproductive age) & 4.4 & 2.9 & \\
Mean age of women registered in the SRS (years) & 21.8 & 20.8 & \\
Mean years of schooling of the women & 1.0 & 1.3 & \\
& & & \multirow{2}{*}{ Percent } \\
Percent of intervals associated with: & & & 9.33 \\
mort (prior child died before the birth of index child) & & & 1.17 \\
mort $_{2}$ (prior child died during the interval) & & & 3.71 \\
mort $_{3}$ (index child died during the interval) & & 0.20
\end{tabular}

\section{RESULTS}

Weibull parametric regression models were fit using streg command in Stata (StataCorp 2003). Frailty options specify the assumed distribution of heterogeneity. The results, in addition to the standard parameter estimates, contain an estimate of the variance of the frailties and a likelihood-ratio test of the null hypothesis that the variance is zero. In all the regression models cited below, the likelihood-ratio test is performed and found to be statistically significant. Moreover, a shared option is also used in all the regression models. The shared option specifies a variable defining those groups for which the frailty is shared, which is analogous to a randomeffects model for panel data (Gutierrez 2002). Identifiers for individual women control for the effect of unobserved heterogeneity resulting from repeated observations of birth intervals within each observed reproductive history.

In Table 2, hazard ratios for the parameters of Model 1 are presented for the main effects of child mortality indicators on the hazard of closing the index-birth interval (column 1), for the interaction of mortality indicators with sex of the index child and of the child born prior to the index child (column 2), and for the interaction of mortality indicators with maternal education and the birth year of the index child (column 3). Hazard ratios reported in Table 2 demonstrate expected covariate relationships with the closing of a birth interval. As birth order increases, the odds of birth-interval closure decline monotonically. The effect of age, controlling for the birth order of the index child, declines as age increases. Mother's educational attainment is associated with a reduced hazard of interval closing. All such effects reflect the role of these variables as 
fertility determinants. As expected, the odds of birth-interval closure are reduced by the birth of a son in both the previous interval and the index interval, demonstrating the direct fertility impact of son preference.

Results for mortality hazard ratios are consistent with the hypotheses of insurance and replacement effects. In Table 2, the main effects of all four mortality indicators are positive and significant. The combined indicator of biological and behavioral replacement, mort 3 is estimated to be 4.5-fold, indicating a pronounced net replacement effect. Moreover, this effect cannot be attributed to biological replacement alone. The hazard ratio associated with mort 2 estimates a 1.9-fold increase in the odds of interval closure if a child born in the previous interval dies immediately prior to the index period. Findings are also consistent with the hypothesis of an insurance effect, although results suggest that replacement motives may be more pronounced than insurance effects. The estimated mort ${ }_{1}$ hazard ratio suggests that the odds of birth-interval closure is enhanced by 33 percent if a child among children born in prior intervals dies. Taken as a set of effects, the hazard ratios in Table 2 demonstrate a pronounced and consistent relationship between childhood mortality and fertility.

Hazard ratios and tests reported in Table 2 examine the effect of the context of rapid reproductive change and sustained son preference on insurance and replacement behavior. Findings attest to the importance of considering the stage of the transition in interpreting the demographic role of gender-preference interactions with insurance and replacement motives. Columns 2 and 3 of Table 2 are provided to illustrate the complexity of these effects and ways in which reduced parameter specifications can change with the addition of interactions to statistical models, leading to possible misinterpretation of results.

Hazard ratios that are estimated for Model 1, and presented in column 2 of Table 2, show the main effects of insurance and replacement. Mort 1 , mort ${ }_{2}$, and mort ${ }_{3}$ main effects are significant, supporting the hypotheses of insurance and replacement. Moreover, the interaction of these effects with the index child's birth year supports the hypothesis that replacement effects increase as the demographic transition progresses. The insurance indicator ( mort $\left._{1}\right)$ is significant as a main effect, but the interaction of insurance with stage of the transition is not. However, the interaction of mort 1 with male index child for the 1984-86 period suggests a transitory conditional insurance relationship. In contrast to the model of main effects presented in Table 2, mort ${ }_{1}$ effects diminish as sets of interaction effects are added to the model. 
Table 2 Hazard ratios for the main and interaction effects of infant and child mortality on the onset of pregnancy, controlling for indexchild birth order, sex, birth year, maternal education, and mother's age at the time of index child's birth

\begin{tabular}{|c|c|c|c|}
\hline \multirow[b]{2}{*}{ Covariate } & \multicolumn{3}{|c|}{ Hazard ratio } \\
\hline & Model 1 & Model 2 & Model 3 \\
\hline \multicolumn{4}{|l|}{ Mortality variable } \\
\hline Mort 1 (prior child died before the birth of index child) & $1.33 * * *$ & $1.36^{* * *}$ & $1.24 * *$ \\
\hline Mort $_{2}$ (prior child died during the interval) & $1.87 * * *$ & $1.86^{* * *}$ & $1.83 * * *$ \\
\hline Mort $_{3}$ (index child died during the interval) & $4.50 * * *$ & $4.09 * * *$ & $4.09 * * *$ \\
\hline Mort $_{4}$ (prior child died within 12 months after the interval) & $2.31 * * *$ & $2.31 * * *$ & $2.27 * * *$ \\
\hline \multicolumn{4}{|l|}{ Birth order of index child } \\
\hline $2(\mathrm{r})$ & 1.00 & 1.00 & 1.00 \\
\hline 3 & $0.80 * * *$ & $0.80 * * *$ & $0.80 * * *$ \\
\hline 4 & $0.57 * * *$ & $0.57 * * *$ & $0.57 * * *$ \\
\hline 5 & $0.43 * * *$ & $0.43 * * *$ & $0.43 * * *$ \\
\hline 6 & $0.32 * * *$ & $0.32 * * *$ & $0.32 * * *$ \\
\hline 7 & $0.24 * * *$ & $0.24 * * *$ & $0.24 * * *$ \\
\hline 8 & $0.15 * * *$ & $0.15 * * *$ & $0.15 * * *$ \\
\hline 9 & $0.14 * * *$ & $0.14 * * *$ & $0.14 * * *$ \\
\hline 10 & $0.11 * * *$ & $0.11 * * *$ & $0.11 * * *$ \\
\hline \multicolumn{4}{|l|}{ Birth year of index child } \\
\hline Prior to 1984 (r) & 1.00 & 1.00 & 1.00 \\
\hline During 1984-86 & $0.71 * * *$ & $0.71 * * *$ & $0.71 * * *$ \\
\hline After 1986 & $0.42 * * *$ & $0.42 * * *$ & $0.37 * * *$ \\
\hline \multicolumn{4}{|l|}{ Sex } \\
\hline Male child born prior to index child & $0.95 * *$ & $0.95 * *$ & $0.95 * *$ \\
\hline Male index child & $0.92 * * *$ & $0.91 * * *$ & $0.91 * * *$ \\
\hline \multicolumn{4}{|l|}{ Mother's education } \\
\hline None $(\mathrm{r})$ & 1.00 & 1.00 & 1.00 \\
\hline Primary & $0.93 *$ & $0.93 *$ & $0.93 *$ \\
\hline Higher & $0.61 * * *$ & $0.61 * * *$ & $0.61 * * *$ \\
\hline \multicolumn{4}{|l|}{ Mother's age at index child's birth } \\
\hline$<20$ & $5.62 * * *$ & $5.62 * * *$ & $5.68 * * *$ \\
\hline $20-24(r)$ & 1.00 & 1.00 & 1.00 \\
\hline $25+$ & $4.27 * * *$ & $4.27 * * *$ & $4.31 * * *$ \\
\hline \multicolumn{4}{|l|}{ Interactions } \\
\hline Mortality type x sex of index child & & 0.96 & 0.97 \\
\hline (Mort 1 ) x (male previous child) & & 1.02 & 1.01 \\
\hline$\left(\right.$ Mort $\left._{2}\right) \times($ male previous child) & & $1.21^{*}$ & $1.21^{*}$ \\
\hline$\left(\mathrm{Mort}_{3}\right) \times($ male index child $)$ & & & \\
\hline \multicolumn{4}{|l|}{ Mortality type $\mathrm{x}$ mother's education } \\
\hline (Mort 1 ) x (Primary) & & & 0.92 \\
\hline (Mort 2$)$ x (Primary) & & & 1.21 \\
\hline (Mort 3$)$ x (Primary) & & & 1.01 \\
\hline (Mort 1$) \times$ (Higher) & & & 1.01 \\
\hline$\left(\right.$ Mort $\left._{2}\right) \times$ (Higher) & & & 1.01 \\
\hline$\left(\mathrm{Mort}_{3}\right) \times($ Higher $)$ & & & 0.96 \\
\hline \multicolumn{4}{|l|}{ Mortality type $\mathrm{x}$ birth year of index child } \\
\hline$\left(\right.$ Mort $\left._{1}\right) \times$ (during 1984-86) & & & 0.98 \\
\hline$\left(\right.$ Mort $\left._{2}\right) \times$ (during 1984-86) & & & 0.89 \\
\hline$\left(\mathrm{Mort}_{3}\right) \times$ (during 1984-86) & & & $0.60 * * *$ \\
\hline$\left(\right.$ Mort $\left._{1}\right) \times($ after 1986) & & & 1.13 \\
\hline$\left(\right.$ Mort $\left._{2}\right) \times($ after 1986) & & & 1.38 \\
\hline$\left(\right.$ Mort $\left._{3}\right) \times($ after 1986) & & & $1.87 * * *$ \\
\hline$-2 \log L$ & 392690 & 392673 & 392401 \\
\hline Likelihood ratio Chi-square (degrees of freedom) & & $17(3) * * *$ & $272(12)^{* * * *}$ \\
\hline
\end{tabular}

$(\mathrm{r})=$ Reference category.

*Significant at $\mathrm{p}<0.05 ; * * \mathrm{p}<0.01 ; * * * \mathrm{p}<0.001$. 
The interaction of mort $_{2}$ and mort $_{3}$ with the sex of the index child and with the year of birth of the index child supports the hypothesis of volitional replacement. As fertility control has increased, the replacement effect has become more pronounced. If a male child dies, the replacement motive is stronger than if the child who dies is female. The absence of significant

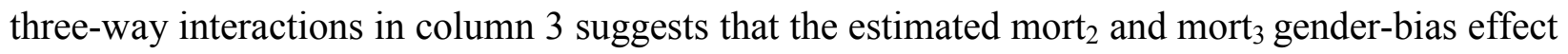
on birth-interval closure is not conditional on the year of the index child's birth. The interaction of mort $_{3}$ with time period is significant and positive for the 1984-86 period, and this interaction increases for the 1987-92 period. Somewhat greater hazard ratios are estimated for the corresponding mort $_{3}$ time period interactions - a 1.9-fold hazard ratio, suggesting that the mortality effects of maternal and household characteristics that are unrelated to replacement effects have grown as the transition progressed.

In summary, results lend consistent support to the child-replacement hypothesis, somewhat less consistent support to the insurance hypothesis, and clear and unequivocal support for the hypothesis that child-replacement effects increase in demographic importance as the demographic transition progresses. Moreover, child-replacement effects interact with sex of index child in ways that are consistent with the hypothesis that the death of male (preferred) children enhances replacement behavior. This interaction is not significant if the stage of the transition is considered in the model, and no evidence is found that the interaction of gender bias with replacement becomes more pronounced as the transition progresses.

\section{DISCUSSION AND CONCLUSION}

Considerable attention has been directed to the relationship between childhood mortality and fertility behavior in Bangladesh. The possible effect of the insurance value of children has been proposed as a key factor in explaining high pretransitional fertility. This analysis, while lending support to the hypothesis of an insurance effect, has demonstrated that its demographic significance is likely to be less prominent than that of replacement behavior. Moreover, insurance behavior is unrelated to the sex of index child, and no evidence has been found that insurance behavior interacts with the stage of the transition. Findings indicate that the insurance motive remains intact even after total fertility declined to fewer than three children per woman. Infant mortality rates remained high throughout the transition, and societal effects of reduced late-childhood mortality have yet to have an impact on insurance-related motives.

The demographic role of child replacement is relatively pronounced, however. The death of an infant in an index birth interval and the death of a child immediately prior to the index interval elevate subsequent fertility. This effect is accentuated by the stage of fertility decline, demonstrating that the volitional role of child replacement is enhanced as contraceptive use and fertility control increase. Son preference also interacts with child replacement in plausible ways, suggesting that the death of a preferred child is likely to evoke the replacement motive. Thus, the well-documented role of gender bias as a determinant of child health and survival is also a factor in child-replacement decisionmaking. The role of sex preference in replacement behavior is unrelated to the index child's year of birth. Although the rapid fertility decline in Bangladesh 
transformed reproductive behavior in less than a generation, no evidence shows that the effect of son preference on replacement motives has changed as the fertility transition has progressed.

\section{Notes}

1 See, for example, Cleland et al. (1994).

2 Similar relationships have been noted in India (Freed and Freed 1989; Murthi et al. 1995).

3 Related qualitative research is reported in LeGrand and Barbieri (2001) and LeGrand et al. (2003).

4 A thana is the primary unit of governance, sometimes referred to as a district. Each thana is an administrative and geographic unit with a population of approximately 200,000.

5 The SRS is described in Mozumder et al. (1991). The SRS was established by conducting a census of extended family households in the sample. The database was used to print a household record book formatted to record changes in resident-member relationships and all demographic events occurring in the three-month interviewing rounds.

6 Routine random cross-sectional interviews with a 15 percent subsample of the SRS households permit comparisons of reinterview data with longitudinal SRS data suggesting that the event undercount of the SRS is less than 1 percent. Prospective inconsistencychecking procedures have minimized misreporting and mistiming of demographic events.

\section{REFERENCES}

Amin, Sajeda and Alaka M. Basu. 2004. "Popular perceptions of emerging influences on mortality and longevity in Bangladesh and West Bengal." Policy Research Division Working Paper No. 186. New York: Population Council.

Chen, Lincoln C., Shamsa Ahmed, Melita Geshe, and W. Henry Mosley. 1974. "A prospective study of birth interval dynamics in rural Bangladesh.” Population Studies 28(2): 277297.

Chen, Lincoln C., Emdadul Huq, and Stan D'Souza. 1981. "Sex bias in the family allocation of food and health care in rural Bangladesh." Population and Development Review 7(1): 5570 .

Clark, Samuel. 1996. "Child survival as a determinant of contraceptive continuation in two areas of rural Bangladesh.” Department of Population Dynamics, Johns Hopkins University School of Hygiene and Public Health. Doctoral dissertation.

Cleland, John, James F. Phillips, Sajeda Amin, and Golam M. Kamal. 1994. The Determinants of Reproductive Change in Bangladesh: Success in a Challenging Environment. 
Washington, DC: The International Bank for Reconstruction and Development/The World Bank.

D’Souza, Stan and Lincoln C. Chen. 1980. "Sex differentials in mortality in rural Bangladesh." Population and Development Review 6(2): 257-270.

Freed, Ruth S. and Stanley A. Freed. 1989. "Beliefs and practices resulting in female deaths and fewer females than males in India." Population and Environment 10(3): 144-161.

Gutierrez, R.G. 2002. "Parametric frailty and shared frailty survival models." The Stata Journal 2: $22-44$.

Hill, Kenneth, Mary Mahy, and Thomas LeGrand. 2001. "Mortality, fertility, and reproductive behavior in Senegal and Zimbabwe." Paper presented at the International Population Conference of the International Union for the Scientific Study of Population, Salvador, Brazil, August.

LeGrand, Thomas K. and Magali Barbieri. 2001. "The demographic transition in sub-Saharan Africa: Effects of child survival on women's ages at first union and childbirth." Unpublished.

LeGrand, Thomas K., Todd Koppenhaver, Nathalie Mondain, and Sara Randall. 2003. "Reassessing the insurance effect: A qualitative analysis of fertility behavior in Senegal and Zimbabwe." Population and Development Review 29(3): 375-403.

LeGrand, Thomas K. and Jo Sandberg. 2005. "Effects of child mortality on fertility: Theoretical complexities and measurement difficulties." Unpublished.

Majumder, Abul Kashem, Marian May, and Prakash Dev Pant. 1997. "Infant and child mortality determinants in Bangladesh: Are they changing?" Journal of Biosocial Science 29(4): 385-399.

Mensch, Barbara Sena. 1985. "The effect of child mortality on contraceptive use and fertility in Colombia, Costa Rica, and Korea.” Population Studies 39(2): 309-327.

Montgomery, Mark R. and Barney Cohen. 1998. "Introduction." In From Death to Birth: Mortality Decline and Reproductive Change. Eds. Mark R. Montgomery and Barney Cohen. Washington, DC: National Academy Press. Pp.1-38.

Mozumder, A.B.M., Khorshed Alam, Michael A. Koenig, James F. Phillips, and S. Murad. 1991. "The Sample Registration System: An innovative system for monitoring demographic dynamics." Asia-Pacific Population Journal 5(3): 63-70.

Muhuri, Pradip Kumar. 1996. "Estimating seasonality effects on child mortality in Matlab, Bangladesh.” Demography 33(1): 98-110. 
Murthi, Mamta, Anne-Catherine Guio, and Jean Drèze. 1995. "Mortality, fertility, and gender bias in India: A district-level analysis." Population and Development Review 21(4): 745782.

Rahman, Mizanur. 1998. "The effect of child mortality on fertility regulation in rural Bangladesh.” Studies in Family Planning 29(3): 268-281.

Rahman, Mizanur, Jalaluddin Akbar, James F. Phillips, and Stan Becker. 1992. "Contraceptive use in Matlab, Bangladesh: The role of gender preference." Studies in Family Planning 23(4): 229-242.

Randall, Sara Claire and Thomas K. LeGrand. 2001. "Is child mortality important? Reproductive decisions, strategies, and outcomes in Senegal." Unpublished.

StataCorp. 2003. Survival Analysis and Epidemiological Tables. Reference Manual, Release 8. College Station, TX: StataCorp.

Wolpin, K.I. 1998. "The impact of infant and child mortality risk on fertility." In From Death to Birth: Mortality Decline and Reproductive Change. Eds.: Mark R. Montgomery and Barney Cohen. Washington, DC: National Academy Press. Pp.74-111. 


\section{POLICY RESEARCH DIVISION WORKING PAPERS}

If still in print, single copies of up to three working papers from 1989 through 2003 are available free of charge.

Beginning with the 2004 issues, working papers are no longer available in print format. Instead they are distributed electronically. As each new paper is completed subscribers are notified by e-mail and a link to the paper is provided.

To subscribe to the Policy Research Division working paper e-mail notification list, or to obtain back issues from 1989 to 2003, please send your request to prdwp@popcouncil.org.

PDFs of recent issues are available at www.popcouncil.org/publications/wp/prd/rdwplist.html

2005

198 Mian Bazle Hossain, James F. Phillips, and Thomas K. LeGrand, "The impact of childhood mortality on fertility in six rural thanas of Bangladesh."

197 Kristine R. Baker, Mary Beth Ofstedal, Zachary Zimmer, Zhe Tang, and Yi-Li Chuang, "Reciprocal effects of health and economic well-being among older adults in Taiwan and Beijing."

196 Mark R. Montgomery and Paul C. Hewett, "Poverty and children's schooling in urban and rural Senegal."

2004

195 Luciana Suran, Sajeda Amin, Lopita Huq, and Kobita Chowdury, "Does dowry improve life for brides? A test of the bequest theory of dowry in rural Bangadesh.”
194 Barbara S. Mensch, Monica J. Grant, Mary P. Sebastian, Paul C. Hewett, and Dale Huntington. "The effect of a livelihoods intervention in an urban slum in India: Do vocational counseling and training alter the attitudes and behavior of adolescent girls?"

193 Amanda Ritchie, Cynthia B. Lloyd, and Monica Grant. "Gender differences in time use among adolescents in developing countries: Implications of rising school enrollment rates."

192 John Bongaarts. "Long-range trends in adult mortality: Models and projection methods."

191 John Koku Awoonor-Williams, Ellie S. Feinglass, Rachel Tobey, Maya N. Vaughan-Smith, Frank K. Nyonator, Tanya C. Jones, and James F. Phillips, "Bridging the gap between evidence-based innovation and national healthsector reform in Ghana."

190 Kelly Hallman, "Socioeconomic disadvantage and unsafe sexual behaviors among young women and men in South Africa." 
189

Toshiko Kaneda, Zachary

Zimmer, and Zhe Tang, "Differentials in life expectancy and active life expectancy by socioeconomic status among older adults in Beijing."

188 Cynthia B. Lloyd and Monica J. Grant, "Growing up in Pakistan: The separate experiences of males and females."

187 Zachary Zimmer, Xianghua Fang, Toshiko Kaneda, Zhe Tang, and Julia Kwong. "Trends and transitions in children's coresidence with older adults in Beijing municipality."

186 Sajeda Amin and Alaka M. Basu. "Popular perceptions of emerging influences on mortality and longevity in Bangladesh and West Bengal."

185 John Bongaarts. "Population aging and the rising cost of public pensions."

184 Mark R. Montgomery and Paul C. Hewett. "Urban poverty and health in developing countries: Household and neighborhood effects.

2003

183 Agnes R. Quisumbing and Kelly Hallman. "Marriage in transition: Evidence on age, education, and assets from six developing countries."
182 Paul C. Hewett, Barbara S. Mensch, and Annabel S. Erulkar, "Consistency in the reporting of sexual behavior among adolescent girls in Kenya: A comparison of interviewing methods."

181 Zachary Zimmer, Linda G. Martin, and Hui-Sheng Lin, "Determinants of old-age mortality in Taiwan."

180 Frank K. Nyonator, J. Koku Awoonor-Williams, James F. Phillips, Tanya C. Jones, and Robert A. Miller, "The Ghana Community-based Health Planning and Services Initiative: Fostering evidence-based organizational change and development in a resourceconstrained setting."

179 John Bongaarts and Griffith Feeney, "Estimating mean lifetime."

178 Elizabeth F. Jackson, Patricia Akweongo, Evelyn Sakeah, Abraham Hodgson, Rofina Asuru, and James F. Phillips, "Women's denial of having experienced female genital cutting in northern Ghana: Explanatory factors and consequences for analysis of survey data."

177 John Bongaarts, "Completing the fertility transition in the developing world: The role of educational differences and fertility preferences."

176 Cynthia B. Lloyd and Paul C. Hewett, "Primary schooling in sub-Saharan Africa: Recent trends and current challenges." 
175 James F. Phillips, Tanya C. Jones, Frank K. Nyonator, and Shruti Ravikumar, "Evidence-based development of health and family planning programs in Bangladesh and Ghana."

174 Geoffrey McNicoll, "Population and development: An introductory view."

173 Paul Demeny, "Population policy: A concise summary."

172 Zachary Zimmer, Napaporn Chayovan, Hui-Sheng Lin, and Josefina Natividad, "How indicators of socioeconomic status relate to physical functioning of older adults in three Asian societies."

171 Sajeda Amin and Nagah H. AlBassusi, "Wage work and marriage: Perspectives of Egyptian working women."

170 Ravai Marindo, Steve Pearson, and John B. Casterline, "Condom use and abstinence among unmarried young people in Zimbabwe: Which strategy, whose agenda?"

169 Zachary Zimmer and Julia Dayton, "The living arrangements of older adults in sub-Saharan Africa in a time of HIV/AIDS."

168 Paul C. Hewett, Annabel S. Erulkar, and Barbara S. Mensch, "The feasibility of computerassisted survey interviewing in Africa: Experience from two rural districts in Kenya." 